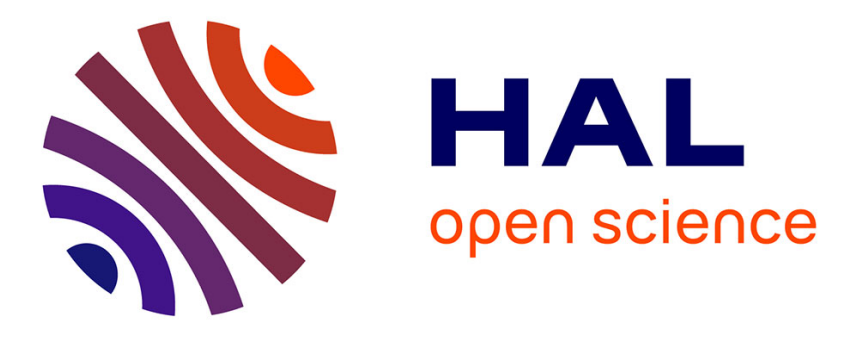

\title{
Dual roles for MEF2A and MEF2D during human macrophage terminal differentiation and c-Jun expression
}

Catherine Aude-Garcia, Véronique Collin-Faure, Huguette Bausinger, Daniel Hanau, Thierry Rabilloud, Claudie Lemercier

\section{To cite this version:}

Catherine Aude-Garcia, Véronique Collin-Faure, Huguette Bausinger, Daniel Hanau, Thierry Rabilloud, et al.. Dual roles for MEF2A and MEF2D during human macrophage terminal differentiation and c-Jun expression. Biochemical Journal, 2010, 430 (2), pp.237-244. 10.1042/BJ20100131 . hal00509879

\section{HAL Id: hal-00509879 \\ https://hal.science/hal-00509879}

Submitted on 17 Aug 2010

HAL is a multi-disciplinary open access archive for the deposit and dissemination of scientific research documents, whether they are published or not. The documents may come from teaching and research institutions in France or abroad, or from public or private research centers.
L'archive ouverte pluridisciplinaire HAL, est destinée au dépôt et à la diffusion de documents scientifiques de niveau recherche, publiés ou non, émanant des établissements d'enseignement et de recherche français ou étrangers, des laboratoires publics ou privés. 


\section{Dual roles for MEF2A and MEF2D during human macrophage terminal differentiation and c-Jun expression}

Catherine AUDE-GARCIA ${ }^{*} \dagger \ddagger^{1}$, Véronique COLLIN-FAURE ${ }^{*} \dagger \ddagger^{1}$, Huguette BAUSINGER $\S \| \mathbb{T}$, Daniel HANAU $\S \| \mathbb{\pi}$, Thierry RABILLOUD ${ }^{*} \dagger \neq$, Claudie LEMERCIER $\uparrow^{2}$

*CEA, DSV, iRTSV, Laboratoire BBSI and † CNRS, UMR 5092, F-38054 Grenoble, France, ‡ Université Joseph Fourier Grenoble 1, France, §Inserm Unité 725 "Biology of Human Dendritic Cells" and ||Etablissement Français du Sang-Alsace, F-67065 Strasbourg, France, đUniversité de Strasbourg, F-67000 Strasbourg, France.

${ }_{2}^{1}$ These authors contributed equally to this work.

${ }^{2}$ to whom correspondence should be addressed (e-mail claudie.lemercier@cea.fr)

Corresponding author: C. Lemercier, CEA-iRTSV-LBBSI, CNRS UMR5092, UJF, 17 rue des martyrs, 38054 Grenoble Cedex; e-mail: claudie.lemercier@cea.fr. Fax: 3343878 4499, Tel: 33438784103

Short title: MEF2A and MEF2D in c-Jun expression during macrophage differentiation 


\section{Synopsis}

Recent reports have evidenced a role for the Myocyte Enhancer Factor 2C (MEF2C) in myelopoiesis, although the precise functions of this transcription factor are still unclear. We show here that MEF2A and MEF2D, two other MEF2 family members, are expressed in human primary monocytes and in higher amounts in monocyte-derived macrophages. High levels of MEF2A/MEF2D heterodimers are found in macrophage-differentiated HL60 cells. Chromatin immunopoprecipitations demonstrate that MEF2A is present on the c-Jun promoter, both in undifferentiated and in macrophage-differentiated cells. Moreover, c-Jun expression is derepressed in undifferentiated cells in the presence of histone deacetylase inhibitor, indicating the importance of chromatin acetylation in this process. We show that MEF2A/D dimers strongly interact with HDAC1, and to a lesser extent with HDAC7 in macrophages, whereas low levels of MEF2A/D:HDAC1 complexes are found in undifferentiated cells or in monocytes. Since trichostatin A does not disrupt MEF2A/D:HDAC1 complexes, we analyzed the potential interaction of MEF2A with p300 histone acetyltransferase, whose expression is upregulated in macrophages. Interestingly, endogenous $\mathrm{p} 300$ only associates with MEF2A in differentiated macrophages, indicating that MEF2A/D could activate c-Jun expression in macrophages through a MEF2A/D:p300 activator complex. The targets of MEF2A/D:HDAC1:HDAC7 multimers remain to be identified. Nevertheless, these data highlight for the first time the possible dual roles of MEF2A and MEF2D human macrophages, as activator or as repressor of gene transcription.

Key words: macrophage, MEF2, histone deacetylase, histone acetyltransferase, c-Jun, chromatin immunoprecipitation.

Abbreviations used: Chip, chromatin immunoprecipitation; FCS, fetal calf serum; HAT, histone acetyltransferase; HDAC, histone deacetylase; M-CSF macrophage colony stimulating factor; MEF2, myocyte enhancer factor 2; TBS, Tris-buffered saline; TSA, trichostatin A. 


\section{Introduction}

Cells of the myeloid lineage play crucial roles in innate immunity. This lineage includes monocytes/macrophages, neutrophils and dendritic cells, cells that are present in the blood and in many tissues where they function as phagocytic cells, antigen-presenting cells, and killing cells. Myeloid cells evolve from a common myeloid progenitor present in the bone marrow which, upon the appropriate stimuli and environment, gives rise to the various myeloid cell types. Several transcription factors have been identified as key regulators of myeloid differentiation [1], primarily through gene inactivation studies in the mouse or through the identification of mutant genes in human diseases [2]. Among these factors are the CCAAT/enhancer binding protein family (C/EBP), PU.1/Spi-1, a positive regulator of myeloid and lymphoid development, the Growth Factor Independent 1 (Gfi1), a protein important for the differentiation toward the neutrophilic and dendritic lineage or the Activator Protein 1 family (AP1, Jun and Fos proteins) involved in the monocyte/macrophage lineage development [3]. Often, these factors cooperate through direct protein: protein interactions to regulate target gene expression [4-5].

Lately, accumulative evidences support a role for the Myocyte Enhancer Factor 2C (MEF2C) in the myeloid lineage [6-8]. Other studies have also shown that MEF2C acts as a cooperating oncogene in myeloid leukaemia although it is unable to induce leukaemogenesis when expressed alone $[9,10]$.

MEF2 belongs to the MADS (MCM1, agamous, deficient, serum response factor) family of transcription factors. There are four vertebrate MEF2 genes (MEF2 A, B, C and D) expressed in distinct but overlapping patterns in embryonic and adult tissues. The N-terminus of MEF2 contains a highly conserved MADS-box and an adjacent MEF2 domain, that both mediate dimerization, DNA-binding and protein-protein interactions [11 and references therein]. The C-terminal regions of MEF2 proteins function as transcriptional activation domains that are divergent among the 4 family members. MEF2, originally identified as a regulator of myogenesis, also plays a role in many developmental programs, including neuronal differentiation, $\mathrm{T}$ and $\mathrm{B}$ lymphocyte differentiation, vascular cell and chondrocyte development [11]. Moreover, the protein is involved in apoptosis, cell survival and proliferation [12]. In each of these cases, the spectrum of target genes activated by MEF2 depends on the specific post-translational modifications (phosphorylation, sumoylation, acetylation) that MEF2 undergoes and on its interaction with cofactors, such as histone deacetylases (HDAC) that repress MEF2 target genes [13-21] and histone acetyltransferases (HAT) that promote MEF2 activity through a local histone acetylation on the MEF2-bound genes [22-25].

Several reports have focused on MEF2C factor in myeloid cells, but little is known on the potential role(s) of the related family members, in particular MEF2A and MEF2D that share a high degree of homology with MEF2C. Therefore we study the expression and functions of these factors in human monocytes and macrophages.

\section{EXPERIMENTAL}

\section{Cell preparation and culture, reagents}

Monocytes were obtained from healthy volunteer blood donors who gave informed consent for the use of their blood cells for research purposes. Monocytes were first isolated by continuous flow centrifugation leukapheresis and counterflow centrifugation elutriation [26] and then subjected to positive immunomagnetic selection with CD14 Miltenyi MicroBeads (Miltenyi Biotec). The cells were then frozen in 90\% fetal calf serum (FCS, PAN BIOTECH) - 10\% DMSO and stored in liquid nitrogen until use. Macrophages were produced from the elutriates obtained from the donors of monocytes by allowing the elutriated cells to adhere for $1 \mathrm{~h} 30$ minutes at $37^{\circ} \mathrm{C}$, before incubating them for 5 days in RPMI 1640 (Sigma-Aldrich Corporation) supplemented with $2 \mathrm{mM}$ L-glutamine, 10\% FCS and $100 \mathrm{ng} / \mathrm{mL} \mathrm{M}-\mathrm{CSF}$ (PeproTech). Macrophages were frozen as monocytes. The promyeloid HL60 cells were grown in RPMI 1640 medium containing 10\% FCS, 2 mM L-Glutamine. PMA was from LC 
Laboratories. 1 $\alpha$, 25-dihydroxy Vitamin D3 (Vit D3) and Trichostatin A (TSA) were from Sigma-Aldrich Corporation. PMA was used at $10 \mathrm{ng} / \mathrm{mL}$ unless otherwise stated and Vit D3 at $100 \mathrm{nM}$.

\section{Cell extracts and Western blotting}

Total cell extracts were obtained by direct lysis in Laemmli sample buffer. Alternatively, cells were lysed in Ripa (10 mM Tris-HCl pH 7.5, $150 \mathrm{mM} \mathrm{NaCl}, 2 \mathrm{mM}$ EDTA, $1 \%$ Igepal CA630 (Sigma-Aldrich Corporation), $0.5 \%$ sodium deoxycholate, $0.1 \%$ SDS $1 \mathrm{mM}$ PMSF, $5 \mathrm{mM} \mathrm{NaF}, 1 \mathrm{mM} \mathrm{Na}_{3} \mathrm{VO}_{4}$ and Complete Mini protease inhibitor (Roche Diagnostics). Equal amounts of protein were separated by SDS-PAGE and blotted onto nitrocellulose (Bio-Rad). Primary antibodies were: MEF2 (C-21) directed against human MEF2A, PU.1, Gfi1, HDAC1 (H-11), HDAC7 (H-273), p300 (N-15 and C-20), c-Jun (H-79), GAPDH, all from Santa Cruz Biotechnology. Monoclonal anti-MEF2D was from BD Transduction Laboratories, antiacetyl-H3 was from Upstate (Millipore). Blots were detected with horseradish peroxidaselabeled secondary antibodies and ECL Plus (GE Healthcare). For immunoprecipitation analysis, we used an anti-mouse or an anti-rabbit secondary antibody specific for the light chains (Jackson ImmunoResearch Laboratories).

\section{Immunofluorescence and Confocal Microscopy}

HL60 (control or PMA) were attached to poly-L-lysine coated slides, fixed in $4 \%$ paraformaldehyde and permeabilized in $0.5 \%$ Triton X-100. After blocking, primary antibodies were applied overnight at $4^{\circ} \mathrm{C}$. Slides were then washed in PBS and the detection was performed with anti-rabbit-Alexa 488 or anti-mouse-Alexa 546 (Molecular Probes). Nuclei were stained with To-Pro3 (Molecular Probes). Images were collected on a Leica TSC-P2 confocal microscope, on a sequential mode for three color acquisitions, and imported in Adobe Photoshop for figure preparation.

\section{Co-immunoprecipitation assays}

Extracts were prepared from $15.10^{6}$ control or PMA cells $(10 \mathrm{ng} / \mathrm{mL}$ for $24 \mathrm{~h})$ using $300 \mu \mathrm{l}$ of extraction buffer (50 mM Tris $\mathrm{HCl}$ pH 7.5, $150 \mathrm{mM} \mathrm{NaCl}, 5 \mathrm{mM}$ EDTA, $1 \mathrm{mM} \mathrm{ZnSO}$, $5 \%$ glycerol, $0.5 \%$ Igepal, $0.5 \%$ sodium deoxycholate, $1 \mathrm{mM}$ PMSF, $5 \mathrm{mM} \mathrm{NaF}$ and protease inhibitors. Lysates were cleared at $13,000 \mathrm{~g}$ for $20 \mathrm{~min}, 4^{\circ} \mathrm{C}$. Supernatants were diluted to reduce Igepal and sodium deoxycholate concentration down to $0.33 \%$, incubated overnight at $4^{\circ} \mathrm{C}$ with $1.5 \mu \mathrm{g}$ of specific antibody (or control IgG) and protein G-agarose PLUS (Santa Cruz Biotechnology) for an additional $2 \mathrm{~h}$. After washes, the bound material was eluted in $100 \mu \mathrm{l}$ of Laemmli sample buffer containing 5\% $\quad \beta$ mercapto-ethanol. For p300 immunoprecipitation, extracts were prepared in Ripa and then diluted to reduce by half the detergent concentrations. Immunoprecipitations were performed with $4 \mu \mathrm{g} / \mathrm{mL}$ of p300 (C-20) antibody or rabbit $\operatorname{IgG}$ overnight at $4{ }^{\circ} \mathrm{C}$ and protein A-agarose as above.

\section{Chromatin immunoprecipitation assays (Chip)}

Chip assays were performed according to Upstate Chromatin immunoprecipitation protocol and crosslinked for 10 min with $1 \%$ formaldehyde directly in culture medium. Sonication of cellular DNA was achieved with a VibraCell sonicator (2 mm tip) using 10 pulses of 12 seconds (amplitude set at 33\%). Each Chip was performed from $3.10^{6}$ cells, starting with a $1 \mathrm{~h}$ pre-clearing with protein A-agarose beads blocked with salmon sperm DNA. Immunoprecipitations were performed overnight at $4^{\circ} \mathrm{C}$ with $2 \mu \mathrm{g}$ of anti-MEF $2 \mathrm{C} 21$ or rabbit IgG. Protein/DNA complexes were collected on protein A-agarose and washed twice successively in low salt wash buffer, high salt wash buffer, Lithium chloride wash complex and TE as described in Upstate protocol. Complexes were eluted in 1\% SDS, $0.1 \mathrm{M} \mathrm{NaHCO} 3$ 
and reverse crosslinked for $4 \mathrm{~h}$ at $65^{\circ} \mathrm{C}$. After proteinase $\mathrm{K}$ treatment and phenol chloroform extraction, the eluted DNA was precipitated and analyzed by PCR using the following primers (5' to 3'): c-Jun for: ATGGGAAGGCCTTGGGGTGACATCATG and c-Jun rev: CTGGGCAGTTAGAGAGAAGGTGAAAAG, GGCAAGGTGAACGTGGATGAAGTTGGTG and $\beta$-globine for: GGAGTGGACAGATCCCCAAAGGACTCAAAG, and the cycling parameters: $95^{\circ} \mathrm{C}$ for 30 $\mathrm{sec}, 63^{\circ} \mathrm{C}$ for $30 \mathrm{sec}, 72^{\circ} \mathrm{C}$ for $40 \mathrm{sec}, 37$ to 40 cycles, $72^{\circ} \mathrm{C}$ for $5 \mathrm{~min}$.

\section{RESULTS}

\section{Human primary macrophages up-regulate MEF2A and MEF2D protein expression.}

MEF2A and MEF2D expressions were analyzed by western blot in human peripheral blood monocytes obtained from healthy donors and in monocyte-derived macrophages from the same donors. The two proteins were detected in monocytes and the amount of MEF2A and MEF2D increased 2 to 3-fold in differentiated macrophages (Figure 1A). In macrophages, MEF2A antibody recognized a doublet, as reported before in several other cells [14, 27].We also observed an up-regulation of the transcription factors PU.1 and c-Jun in macrophages, in comparison to monocytes, whereas Gfil levels were close in both populations. Thus, MEF2A and MEF2D are upregulated like PU.1 and c-Jun transcription factors during terminal differentiation toward the macrophage stage.

To perform biochemical analysis, and since we could not work routinely with fresh human blood cells, we utilized the human promyeloid HL60 cell line, which has the ability to differentiate into macrophages upon PMA treatment. In that case, cells exited cell cycle, became adherent and expressed high levels ( $>95 \%$ positive after $24 \mathrm{~h}$ ) of CD11b or CD54 (not shown). Comparison of the electrophoretic migration of MEF2A and MEF2D in human primary macrophages and HL60 macrophages reveals an identical pattern in the two samples, both for MEF2A and MEF2D, suggesting that HL 60 cells produce the same MEF2 proteins than the primary macrophages (Figure 1B).

We then analyzed in detail the differentiation of HL60 cells in macrophages. Even at the lowest dose of PMA tested, we observed an up-regulation of the expression of both MEF2A and MEF2D in macrophages as compared to undifferentiated cells (Figure 1C and [28]) Thereafter we routinely worked at $10 \mathrm{ng} / \mathrm{ml}$ of PMA since this dose consistently gives high level of MEF2A/D, as well as CD11b and CD54 differentiation markers, without altering the cell viability at $24 \mathrm{~h}$. Immunofluorescence detection confirmed that PMA treatment upregulated endogenous nuclear localized MEF2A and MEF2D (Figure 1D-E). Finally, as observed in human macrophages, c-Jun and PU.1 increased in HL60 macrophages, while Gfi1 and $\mathrm{C} / \mathrm{EBP} \alpha$, two factors important for the granulocytic pathway, decreased (Figure 1C). Collectively, these data indicate that HL60 cells recapitulate the proper expression of MEF2A and MEF2D, so that this cell line can be used for further biochemical analysis.

\section{MEF2A and MEF2D form heterodimers in HL60 cells}

In HeLa cells and in heart, MEF2A and MEF2D associate as heterodimers [29, 30]. Therefore we searched for potential endogenous interaction between MEF2 proteins in myeloid cells. Immunoprecipitations were performed with anti-MEF2D from undifferentiated or PMAdifferentiated HL60 and analyzed for the presence of MEF2A. Our data indicated that MEF2A specifically co-precipitated with MEF2D in both conditions but not with an irrelevant isotype (Figure 2A and 2B). Reciprocal immunoprecipitation also detected MEF2A:MEF2D complexes (Figure 2C). These complexes seemed stable as they were resistant to Ripa extraction and immunoprecipitations (not shown). A quantification attempt suggested that, in HL60 cells, there is an important fraction of MEF2A-MEF2D heterodimer (supplemental Figure 1). Together, these data indicate that MEF2A and MEF2D heterodimerize in HL60 and that more MEF2A:MEF2D dimers are found in macrophages. 


\section{c-Jun as a target of MEF2A and MEF2D in HL60 cells}

It is known for long that the proto-oncogene c-Jun is induced during macrophage differentiation [31]. Accordingly we found high levels of c-Jun protein in human macrophages, whereas monocytes have a much lower amount of c-Jun (Figure 1A). One possible target gene of MEF2 in myeloid cells is $c-J u n$, whose promoter binds MEF2 in vitro in HeLa cells $[29,32]$ (Figure 3A). To test this possibility in HL60, we performed a time course analysis of c-Jun expression in PMA-differentiated cells. MEF2A and MEF2D proteins were induced within $2 \mathrm{~h}$ of treatment, before c-Jun, whose up-regulation was evidenced after $4 \mathrm{~h}$ (Figure 3B). These data support the idea that c-Jun is regulated by MEF2 in HL60.

However, despite this emerging evidence, the binding of MEF2 on the c-jun promoter has not been documented in vivo. Therefore, we performed chromatin immunoprecipitation (Chip) to analyze MEF2A binding on the c-Jun promoter in undifferentiated cells and in macrophages. Indeed MEF2A binds to the c-Jun promoter (Figure 3C), but not to the $\beta$-globin gene that does not possess a MEF2 binding site. Moreover, no c-Jun promoter was amplified when Chips were performed with rabbit igG. Surprisingly, MEF2A binding was not superior in macrophages as compared to undifferentiated cells. In fact, we consistently observed a moderate decrease of MEF2A binding on the c-Jun promoter in macrophages. These data were reproduced five times with independent cell cultures and various PCR cycle numbers (37 to 40). Thus, MEF2A expression is induced in macrophages, but this transcription factor does not associate in larger amount to the c-Jun promoter in these cells. These data raised the question of the real role of MEF2A in $c$-Jun gene expression.

The activity of MEF2 proteins can be modulated through protein:protein interaction, notably with HDAC and HAT. Interaction between MEF2 and HDACs is predicted to repress MEF2A target genes in HL60. Therefore we reasoned that a disruption or an inhibition of theses interactions should release the HDACs repression on MEF2 bound genes. Thus, we modified the chromatin acetylation state using HDAC inhibitors and we analyzed c-Jun expression in response to chromatin modification. In undifferentiated cells that normally do not express this protein, we observed a dose-dependent induction of c-Jun after a $6 \mathrm{~h}$ treatment with TSA, a class I and class II HDAC inhibitor (Figure 4A). This was accompanied by a marked increase on histone $\mathrm{H} 3$ acetylation, and no changes in MEF2A and MEF2D levels. We then examined c-Jun regulation in HL60 treated with PMA, with or without TSA for 6 hrs. The highest level of c-Jun induction was obtained in the presence of combined PMA and TSA which coincide with the highest level of histone acetylation and MEF2A/D expression (Figure 4B). Together these data strongly suggest that the $c$-Jun gene responds quickly to HDAC inhibition and to increased histone acetylation level.

\section{Endogenous interactions between MEF2A/D and class I and class II HDAC}

MEF2 has been reported to interact with chromatin modifiers, directly as in the case of the histone deacetylases HDAC4, HDAC5, HDAC7 and HDAC9 [13-18] or with the histone acetyltransferase $\mathrm{p} 300$ in muscle cells $[22,25]$ or in lymphocytes $[20,23]$, or indirectly with HDAC1, HDAC2 or HDAC3 $[25,26]$. Therefore, we performed coimmunoprecipitations to detect such interactions with MEF2A and MEF2D in HL60. Figure 5A shows that MEF2A and MEF2D co-precipitated with HDAC1 in control and PMA treated cells. However, higher levels of HDAC1 bound to MEF2A or MEF2D were found in differentiated cells. Reciprocal immunoprecipitations with an anti-HDAC1 antibody confirmed these interactions. Moreover, although HDAC1 levels were similar in all conditions, we obtained a much larger amount of MEF2D:HDAC1 complexes in macrophages than in monocytes (Figure 5B). So during terminal differentiation, MEF2A and MEF2D are both up-regulated and associated with the ubiquitous deacetylase HDAC1, but not with HDAC3 (not shown), a related class I HDAC, at least in the conditions tested.

We also analyzed the putative interaction of MEF2 with class II HDAC, notably with endogenous HDAC7, which expression was induced in HL60 macrophages (Figure 5C). Immunoprecipitation with anti-MEF2A allowed the detection of HDAC7 in differentiated cells only. Moreover, HDAC1 was also present in HDAC7 immunoprecipitate (Figure 5C). 
Together, these results indicate that large amounts of MEF2A/D: HDACs complexes are found in HL60 macrophages, as compared to undifferentiated cells or monocytes.

Finally, we tested whether TSA could disrupt MEF2A/D-HDAC1 interaction in control or PMA-treated cells. After an immunoprecipitation with anti-MEF2A, similar amounts of MEF2A:HDAC1 complexes were obtained with or without TSA, indicating that TSA does not prevent HDAC1 binding to MEF2A/D (Figure 5D), raising the possibility that another fraction of the MEF2A/D pool, not bound to $\mathrm{HDAC1}$, possibly interacts with an acetyltransferase in order to up-regulate c-Jun expression.

\section{MEF2 associates with p300 in HL60 macrophages}

In other cellular systems, it has been shown that MEF2 interacts with p300 HAT [20, 22-25]. To address this possibility, we first performed an immunolocalization of endogenous p300 and MEF2 (anti-MEF2D) in undifferentiated cells and PMA-differentiated HL60 macrophage. This experiment showed that p300 is up-regulated like MEF2D (and MEF2A, figure 1D) in HL60 macrophages and it indicated that p300 and MEF2D partially co-localized in the nucleus of PMA-treated cells (Figure 6A and supplemental figure 2). Next, we performed an immunoprecipitation experiment to visualize potential endogenous MEF2A:p300 complexes. MEF2A was detected in the anti-p300 immunoprecipitate obtained from PMA-differentiated cells (Figure 6B), whereas the control rabbit IgG only showed a non-specific background, also observed with irrelevant antibodies (not shown). Moreover, we failed to detect HDAC1 (figure 6B) and HDAC3 (not shown) in the MEF2A:p300 complexes. These data indicated that a fraction of MEF2A specifically associates with p300 and that this potential activator complex might activate $c$-Jun gene expression during macrophage terminal differentiation.

\section{DISCUSSION}

In this study, we provide evidence for the expression of endogenous MEF2A and MEF2D proteins in primary human blood monocytes and macrophages. We show that MEF2A and MEF2D are upregulated during terminal differentiation in macrophages and we characterize the interactions of these factors with chromatin modifiers during terminal differentiation in a myeloid model. Chip assays demonstrate that MEF2A is present on the $c$ Jun promoter and our data on endogenous proteins indicate that MEF2A and MEF2D heterodimerize and interact with HDAC1 and HDAC7 deacetylases or with p300 histone acetyltransferase during macrophage differentiation.

Conditional deletions of MEF2C in the bone marrow resulted in no haematopoietic abnormalities, indicating that MEF2C is dispensable for steady state myelopoiesis [6-8]. However, Stehling et al. found that MEF2C deficiency was associated to an enhanced myeloid output, indicating that MEF2C normally repress the myeloid cell fate [8]. This data is somewhat controversial with the miR-223 null mice data since mutant mice have more MEF2C transcripts and an increased number of peripheral granulocytes [7]. The third study reports that MEF2C is a pivotal modulator of the myeloid cell fate in response to external stimuli, and it favors monocytic differentiation at the expense of the granulocytic differentiation [6]. Together, these reports clearly support a role for MEF2C in myelopoiesis, but it is still unclear at which level $M E F 2 c$ deletion precisely affects myeloid differentiation. Even though MEF2A and MEF2D proteins are present in mouse and human primary myeloid cells [33, this study], their expression has not been taken in account in the various hematopoietic $M E F 2 c$ mutant mice and their potential role(s) have not been studied. Our results reveal that MEF2A and MEF2D associate both with repressors and activators of gene transcription, suggesting that these factors are fully operational for the gene regulation program associated with macrophage terminal differentiation.

We show that MEF2A and MEF2D interact with at least two deacetylases, HDAC1 and HDAC7, during macrophage terminal differentiation. While MEF2:HDAC7 binding is probably direct, as described before for class II deacetylase [14-18], HDAC1 has not been shown to interact directly with MEF2. However, in T lymphocytes, Youn et al. reported that 
MEF2 form a complex with the calcineurin binding protein 1 (cabin1), a repressor that binds to $\mathrm{mSin} 3 \mathrm{~A}$ and its associated deacetylases HDAC1 and HDAC2 [20]. We do not know to date whether this or a related repressor complex exists in HL60 or in primary macrophages, but cabin1 mRNA are widely expressed, including in leukocytes.

As in the case of class II HDACs, the MADS-box/MEF2 domains of MEF2 proteins constitute the interface region with Cabin1 [34]. Surprisingly, the MADS-box domain of MEF2A or MEF2C is also the site of interaction with p300 [22, 24], suggesting that p300/HDAC7 or potentially p300/cabin1:Sin3:HDAC1 binding to MEF2 are mutually exclusive. Our data show that the two types, activator or repressor, MEF2A/D complexes exist in HL60 macrophages, suggesting that MEF2A/D could both repress and activate gene transcription.

A critical question is how MEF2 switches from a repressor to an activator status and what are the signals implicated in its transcriptional activities. In muscle cells, class II HDACs are phosphorylated upon differentiation signals and calcium signaling, leading to the dissociation of MEF2:HDAC, the export of class II HDAC to the cytoplasm and the transcriptional activation of MEF2 through the recruitment of p300. Also, in T lymphocytes, MEF2 associates with the repressors HDAC7 and cabin1, which inhibit the orphan receptor nuclear nur77 expression $[20,34,35]$. Activation of nur 77 is achieved through the recruitment of p300 acetyltransferase by MEF2, and in this case as well, the repressor/activator switch is dependent on a calcium signaling pathway [23]. A slightly different mechanism might happen in the case of $c$-Jun activation during macrophage induced differentiation since MEF2A is bound in vivo to the MEF2-binding site of the c-Jun gene. In undifferentiated HL60, low levels of MEF2A/D:HDAC1 complexes could repress c-Jun gene transcription, although others factors than MEF2 are implicated in the control of this gene. Upon induced differentiation, HDAC1 could be released from MEF2A/D through a competition mechanism between cabin1 and p300, which both target the MADS-box/MEF2 domain of MEF2 [20]. This mechanism is different from the one described for c-Jun regulation in vascular smooth muscle cells, which seems to be based on an HDAC4:MEF2A repressor complex [36], as we could not detect this complex in macrophages or in undifferentiated HL60.

A puzzling question concerns the identification of the genes repressed by MEF2A/D in differentiated macrophages. Indeed, the highest levels of MEF2A/D:HDAC1/HDAC7 complexes were observed in these cells suggesting that MEF2A/D probably down-regulated a set of genes during macrophage differentiation. Large scale studies at the genomic level will be necessary to address this point. Nevertheless, our data highlight for the first time the potential dual roles of MEF2A and MEF2D in macrophages, as activator or as repressor of gene transcription.

\section{AUTHOR CONTRIBUTION}

V. Collin-Faure and H. Bausinger, performed experiments, analyzed data, corrected the manuscript. C. Aude-Garcia designed and performed some experiments, analyzed data, corrected the manuscript. D. Hanau and T. Rabilloud analyzed data and corrected the manuscript. C. Lemercier designed and supervised the research project, performed experiments, analyzed data, wrote the manuscript.

\section{FUNDING}

This work was supported by the CNRS, the University Joseph Fourier, the CEA Grenoble and INSERM. C. Lemercier is an employee of the "Institut National de la Santé et de la Recherche Médicale“ (INSERM).

The authors do not have any conflict of interest to declare.

\section{ACKNOWLEDGMENTS}


We thank M.-J. Rabiet and F. Boulay for HL60 cells and advices on cell maintenance, D. Grunwald for assistance with confocal microscopy (CEA-iRTSV microscopy facility).

\section{REFERENCES}

1 Friedman, A. D. (2007) Transcriptional control of granulocyte and monocyte development. Oncogene 26, 6816-6828

2 Person, R. E., Li, F. Q., Duan, Z., Benson, K. F., Wechsler, J., Papadaki, H. A., Eliopoulos, G., Kaufman, C., Bertolone, S. J., Nakamoto, B., Papayannopoulou, T., Grimes, H. L., and Horwitz, M. (2003) Mutations in proto-oncogene GFI1 cause human neutropenia and target ELA2. Nat. Genet. 34, 308-312

3 Lord, K. A., Abdollahi, A., Hoffman-Liebermann, B., and Liebermann, D. A. (1993) Proto-oncogenes of the fos/jun family of transcription factors are positive regulators of myeloid differentiation. Mol. Cell. Biol. 13, 841-851

4 Rangatia, J., Vangala, R. K., Treiber, N., Zhang, P., Radomska, H., Tenen, D. G., Hiddemann, W., and Behre, G. (2002) Downregulation of c-Jun expression by transcription factor C/EBPalpha is critical for granulocytic lineage commitment. Mol. Cell. Biol. 22, 8681-8694

5 Grondin, B., Lefrancois, M., Tremblay, M., Saint-Denis, M., Haman, A., Waga, K., Bédard, A., Tenen, D. G., and Hoang, T. (2007) c-Jun homodimers can function as a context-specific coactivator. Mol. Cell. Biol. 27, 2919-2933

6 Schüler, A., Schwieger, M., Engelmann, A., Weber, K., Horn, S., Müller, U., Arnold, M. A., Olson, E. N., and Stocking, C. (2008) The MADS transcription factor Mef2c is a pivotal modulator of myeloid cell fate. Blood 111, 4532-4541

7 Johnnidis, J. B., Harris, M. H., Wheeler, R. T., Stehling-Sun, S., Lam, M. H., Kirak, O., Brummelkamp, T. R., Fleming, M. D., and Camargo, F. D. (2008) Regulation of progenitor cell proliferation and granulocyte function by microRNA-223. Nature 451, $1125-1129$

8 Stehling-Sun, S., Dade, J., Nutt, S. L., DeKoter, R. P., and Camargo, F. D. (2009) Regulation of lymphoid versus myeloid fate 'choice' by the transcription factor MEF2c. Nature Immunology 10, 289-296

9 Du, Y., Spence, S. E., Jenkins, N. A., and Copeland, N. G. (2005) Cooperating cancergene identification through oncogenic-retrovirus-induced insertional mutagenesis.Blood 106, 2498-2505

10 Krivtsov, A. V., Twomey, D., Feng, Z. Stubbs, M. C., Wang, Y., Faber, J., Levine, J. E., Wang, J., Hahn, W. C., Gilliland, D. G., Golub, T. R., and Armstrong, S. A. (2006) Transformation from committed progenitor to leukaemia stem cell initiated by MLLAF9. Nature 442, 818-822

11 Potthoff, M. J., and Olson, E. N. (2007) MEF2: a central regulator of diverse developmental programs. Development 134, 4131-4140

12 McKinsey, T. A., Zhang, C. L., and Olson, E. N. (2002) MEF2: a calcium-dependent regulator of cell division, differentiation and death. Trends Biochem. Sci. 27, 40-47

13 Miska, E. A., Karlsson, C., Langley, E., Nielsen, S. J., Pines, J., and Kouzarides, T. (1999) HDAC4 deacetylase associates with and represses the MEF2 transcription factor. $E M B O . J .18,5099-5107$

14 Lemercier, C., Verdel, A., Galloo, B., Curtet, S., Brocard, M.-P., and Khochbin, S. (2000) mHDA1/HDAC5 histone deacetylase interacts with and represses MEF2A transcriptional activity. J. Biol. Chem. 275, 15594-15599

15 Lu, J., McKinsey, T. A., Zhang, C. L., and Olson, E. N. (2000) Regulation of skeletal myogenesis by association of the MEF2 transcription factor with class II histone deacetylases. Mol. Cell 6, 233-244

16 Dressel, U., Bailey, P. J., Wang, S. C., Downes, M., Evans, R. M., and Muscat, G. E. (2001) A dynamic role for HDAC7 in MEF2-mediated muscle differentiation. J. Biol. Chem. 276, 17007-17013

17 Kao, H. Y., Verdel, A., Tsai, C. C., Simon, C., Juguilon, H., and Khochbin, S. (2001) Mechanism for nucleocytoplasmic shuttling of histone deacetylase 7.J. Biol. Chem. 276, 47496-47507 
18 Zhang, C. L., McKinsey, T. A., Chang, S., Antos, C. L., Hill, J. A., and Olson, E. N. (2002) Class II histone deacetylases act as signal-responsive repressors of cardiac hypertrophy. Cell 110, 479-488

19 Fischle, W., Dequiedt, F., Hendzel, M. J., Guenther, M. G., Lazar, M. A., Voelter, W., and Verdin, E. (2002) Enzymatic activity associated with class II HDACs is dependent on a multiprotein complex containing HDAC3 and SMRT/N-CoR. Mol. Cell 9, 45-57

20 Youn, H. D., and Liu, J. O. (2000) Cabin1 represses MEF2-dependent Nur77 expression and $\mathrm{T}$ cell apoptosis by controlling association of histone deacetylases and acetylases with MEF2. Immunity 13, 85-94

21 Grégoire, S., Xiao, L., Nie, J., Zhang, X., Xu, M., Li, J., Wong, J., Seto, E., and Yang, X. J. (2007) Histone deacetylase 3 interacts with and deacetylates myocyte enhancer factor 2. Mol. Cell. Biol. 27, 1280-1295

22 Sartorelli, V., Huang, J., Hamamori, Y., and Kedes, L. (1997) Molecular mechanisms of myogenic coactivation by p300: Direct interaction with the activation Domain of MyoD and with the MADS Box of MEF2C . Mol. Cell. Biol. 17, 1010-1026

23 Youn, H. D., Chatila, T. A., and Liu, J. O. (2000) Integration of calcineurin and MEF2 signals by the coactivator p300 during T-cell apoptosis. EMBO.J.19, 4323-4331

24 De Luca, A., Severino, A., De Paolis, P., Cottone, G., De Luca, L., De Falco, M., Porcellini, A., Volpe, M., and Condorelli, G. (2003) P300/cAMP-response-elementbinding-protein (CREB)-binding protein (CBP) modulates co-operation between myocyte enhancer factor 2A (MEF2A) and thyroid hormone receptor-retinoid $\mathrm{X}$ receptor. Biochem. J. 369, 477-484

25 Ma, K., Chan, J. K., Zhu, G., and Wu, Z (2005) Myocyte enhancer factor 2 acetylation by p300 enhances its DNA binding activity, transcriptional activity, and myogenic differentiation. Mol. Cell. Biol. 25, 3575-3582

26 Faradji, A., Bohbot, A., Schmitt-Goguel, M., Siffert, J. C., Dumont, S., Wiesel, M. L., Piemont, Y., Eischen, A., Bergerat, J. P., Bartholeyns, J., Poindron, P., Witz, J. P., and Oberling, F. (1994) Large scale isolation of human blood monocytes by continuous flow centrifugation leukapheresis and counterflow centrifugation elutriation for adoptive cellular immunotherapy in cancer patients. J. Immunol. Methods 174, 297309

27 Kaushal, S., Schneider, J. W., Nadal-Ginard, B., and Mahdavi, V. (1994) Activation of the myogenic lineage by MEF2A, a factor that induces and cooperates with MyoD. Science 266, 1236-1240

28 Shin, H.M., Seoh, J.Y., Chung, H.Y., Choi, S.J., Hahn, M.J., Kang, J.S., Choi, M.S., Han, T.H. (1999) Requirement of MEF2D in the induced differentiation of HL60 promyeloid cells. Mol. Immunol. 36, 1209-1214

29 Ornatsky, O. I., and McDermott, J. C. (1996) MEF2 protein expression, DNA binding specificity and complex composition, and transcriptional activity in muscle and nonmuscle cells. J. Biol. Chem. 271, 24927-24933

30 Naya, F. J., Black, B. L., Wu, H., Bassel-Duby, R., Richardson, J. A., Hill, J. A., and Olson, E. N. (2002) Mitochondrial deficiency and cardiac sudden death in mice lacking the MEF2A transcription factor. Nat. Med. 8, 1303-1309

31 Gaynor, R., Simon, K., and Koeffler, P. (1991) Expression of c-jun during macrophage differentiation of HL-60 cells. Blood 77, 2618-2623

32 Han, T . H, and Prywes, R. (1995) Regulatory role of MEF2D in serum induction of the c-jun promoter. Mol. Cell. Biol. 15, 2907-2915

33 Kim, S. O., Ono, K., Tobias, P. S., and Han, J. (2003) Orphan nuclear receptor nur77 is involved in caspase-independent macrophage cell death. J. Exp. Med. 197, 14411452

34 Youn, H. D., Sun, L., Prywes, R., Liu, and J. O. (1999) Apoptosis of T cells mediated by $\mathrm{Ca}^{2+}$-induced release of the transcription factor MEF2. Science $\mathbf{2 8 6}, 790-793$

35 Dequiedt, F., Kasler, H., Fischle, W, Kiermer, V., Weinstein, M., Herndier, B. G., and Verdin, E. (2003) HDAC7, a thymus-specific class II histone deacetylase, regulates Nur77 transcription and TCR-mediated apoptosis. Immunity 18, 687-698

36 Gordon, J.W., Pagiatakis, C., Salma, J., Du, M., Andreucci, J.J., Zhao, J., Hou, G., Perry, R.L., Dan, Q., Courtman, D., Bendeck, M.P., McDermott, J.C. (2009) Protein 
kinase A-regulated assembly of a MEF2 : HDAC4 repressor complex controls c-Jun expression in vascular smooth muscle cells. J. Biol. Chem. 284, 19027-19042 


\section{Figure Legends}

Figure 1: Accumulation MEF2A and MEF2D in human primary macrophages.

(A) Human peripheral blood monocytes (Mono) and monocyte-derived macrophages (Macro) extracts were analyzed by western blot with the indicated antibodies. (B) MEF2A and MEF2D in human primary macrophages versus HL60 macrophages (PMA $10 \mathrm{ng} / \mathrm{mL}$ for 24 h). Extracts were migrated on the same gel transferred to nitrocellulose and incubated with anti-MEF2A or anti-MEF2D as indicated. Protein markers in kDa. For primary macrophages, a lower amount of proteins was loaded onto the gel due to shortage of sample. Note the slight migration difference between MEF2A and MEF2D. (C) HL60 recapitulates the proper expression of MEF2A and MEF2D during PMA-induced differentiation. Cells were grown for $24 \mathrm{~h}$ in the presence of 0 (control: C), 2.5, 5 or $10 \mathrm{ng} / \mathrm{mL}$ of PMA. Ripa extracts were analyzed by western blot with the indicated antibodies. (D) MEF2A and MEF2D (E) accumulate in the nucleus of PMA-differentiated HL60 (24 h, $10 \mathrm{ng} / \mathrm{mL})$. Immunofluorescence and confocal microscopy analysis. Single optical sections are shown. Scale bars: $10 \mu \mathrm{m}$.

\section{Figure 2: MEF2A and MEF2D heterodimerize in HL60 cells.}

(A, B) Cell extracts prepared from undifferentiated (C) or PMA-differentiated HL60 (PMA), were submitted to immunoprecipitations with a MEF2D antibody or an irrevelant isotype. Analysis by western blot with anti-MEF2A (A) and anti-MEF2D (B). Lysates: cell extracts before immunoprecipitation. (C) Reciprocal immunoprecipitation as in (A-B) with antiMEF2A or rabbit IgG and detection with anti-MEF2D.

Figure 3: MEF2A binds to the $c$-Jun promoter in vivo.

(A) The MEF2 binding site in the human $c$-Jun promoter. The thick black arrows represent the primers used for PCR in Chip assays. (B) Time course analysis of MEF2A, MEF2D and c-Jun during HL60 differentiation in macrophages (10 ng/mL of PMA). Extracts were prepared at the indicated times ( 0 to $24 \mathrm{~h}$ ) after PMA addition and analyzed by western blot. C: control without PMA. (C) Chromatin immunoprecipitation on the c-Jun promoter with anti-MEF2A. Crosslinked chromatin obtained from control HL60 cells (C) or PMA differentiated cells, $10 \mathrm{ng} / \mathrm{ml}$ for $24 \mathrm{~h}(\mathrm{P})$ were immunoprecipitated with anti-MEF2A or rabbit IgG. The immunoprecipitated chromatin was amplified by PCR using c-Jun or $\beta$-globin ( $\beta$-Glo) primers. Input: total chromatin before immunoprecipitation. $\mathrm{H}_{2} \mathrm{O}$ : no chromatin template. Two independent experiments are presented.

\section{Figure 4: c-Jun is synergistically induced by PMA and HDAC inhibitors during} macrophage differentiation.

(A) Undifferentiated HL60 cells were incubated with increasing concentrations of TSA for 6 h. Total cell extracts were prepared and analyzed by western blot. (B) HL60 cells were incubated with PMA $(10 \mathrm{ng} / \mathrm{mL})$ and/or TSA $(150 \mathrm{mM})$ for $6 \mathrm{~h}$. Total extracts were prepared and analyzed as in (A) by western blot. The lower panels in (A) and (B) show core histones on a coomassie-stained gel of the cell extracts.

Figure 5: MEF2A:MEF2D interact with HDAC1 and HDAC7 mostly in macrophagedifferentiated cells.

(A) Cell extracts were prepared from control (C) or HL60 macrophage (P), and immunoprecipitated with rabbit IgG, anti-MEF2A or anti-HDAC1. The eluted material was analyzed by western blot with the indicated antibodies. (B) Immunoprecipitations were performed on control (C) or vitamin D3 (D3) monocyte-differentiated HL60 (left panel) or on control and PMA differentiated HL60 (right panel) with an anti-MEF2D or an irrelevant (irrel.) isotype. The presence of HDAC1 and MEF2D were analyzed by western blot. (C) Control or PMA-treated HL60 lysates were submitted to immunoprecipitation with antiMEF2A or rabbit IgG. The presence of HDAC7, MEF2A and HDAC1 in the immunoprecipitates was analyzed by western blot. (D) TSA does not disrupt MEF2A:HDAC1 interactions. HL60 cells were grown with $(10 \mathrm{ng} / \mathrm{mL})$ or without PMA for $24 \mathrm{~h}$, in the presence (+) or in absence (-) of $150 \mathrm{mM}$ of TSA for the last $6 \mathrm{~h}$. When TSA was present in the experiment, all the subsequent steps were done in the presence of $10 \mathrm{mM}$ sodium butyrate 
to maintain HDAC inhibition. Extracts were immunoprecipitated with anti-MEF2A and analyzed by western blot with anti-MEF2A and anti-HDAC1. Left: cell lysates before the immunoprecipitation, right: immunoprecipitation with the anti-MEF2A antibody.

Figure 6: Endogenous p300 histone acetyltransferase interacts with MEF2A in macrophages.

(A) Co-localization of MEF2D and p300 in HL60 macrophages. Control or PMA differentiated HL60 (10 ng/mL for $24 \mathrm{~h})$ were attached to poly-L-lysine coated slides and process for immunofluorescent staining with mouse MEF2D and rabbit p300 antibodies. DNA was counterstained with To-Pro3. Acquisitions were obtained on a confocal microscope. Scale bars: $10 \mu \mathrm{m}$. (B) Extracts prepared from undifferentiated (control: C) or PMA-differentiated HL60 (10 ng/mL for $24 \mathrm{~h})$ were immunoprecipitated with anti-p300 (ip p300) or rabbit IgG (ip rIg). Immunoprecipitates were analyzed by western blot with antiMEF2A (top), p300 (middle) and HDAC1 (bottom). NS indicates a non-specific band obtained with rabbit IgG and migrating just below MEF2A. 

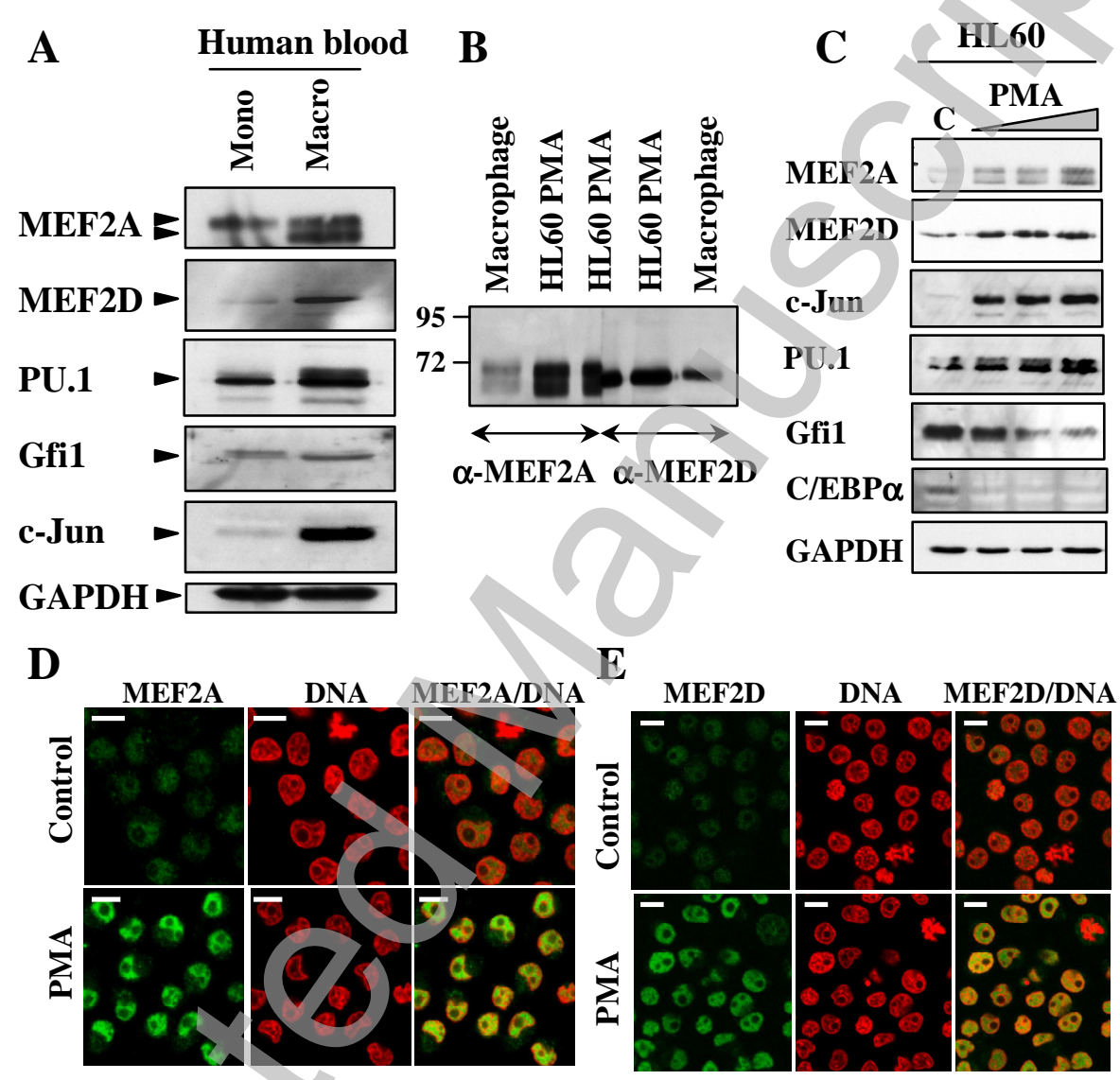

Figure 1 
A

ip ip

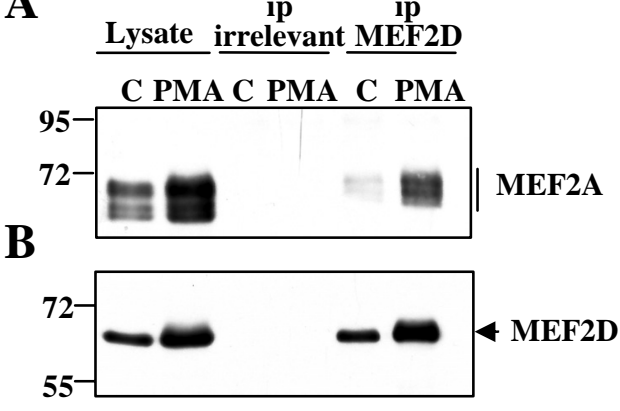

C Lysate ip $_{\text {MEF2A }}^{\text {ip }_{\text {IgG }}}$

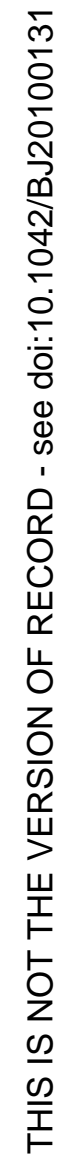

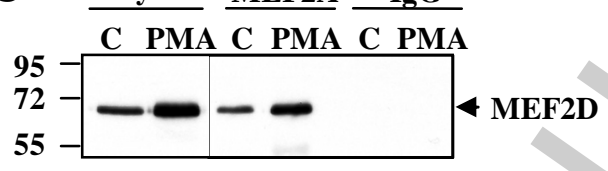

Figure 2 


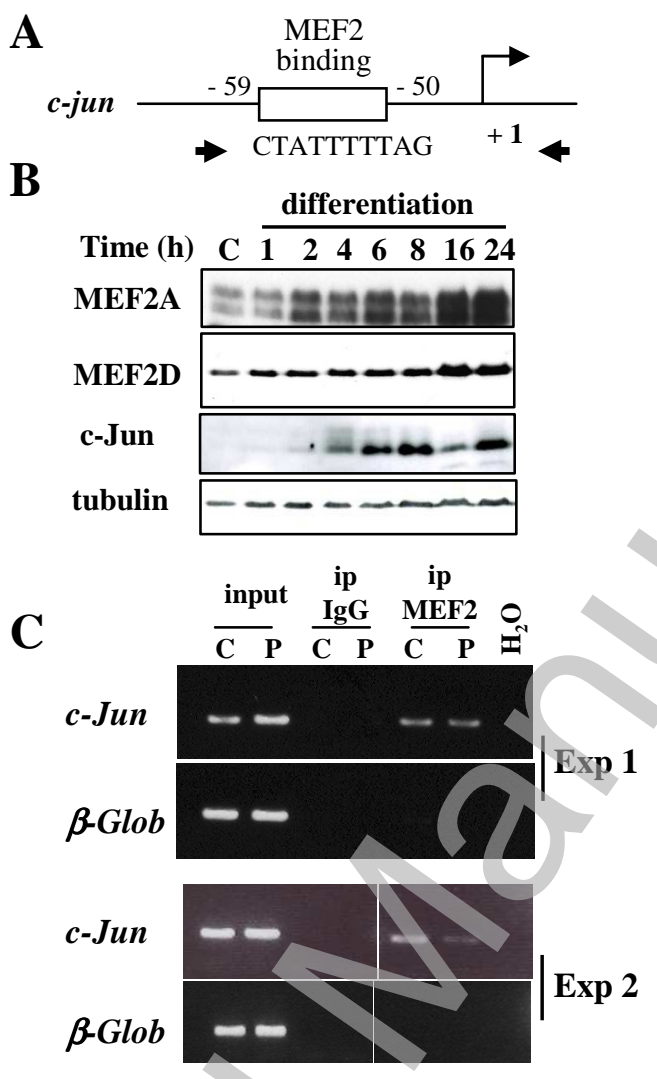

Figure 3 


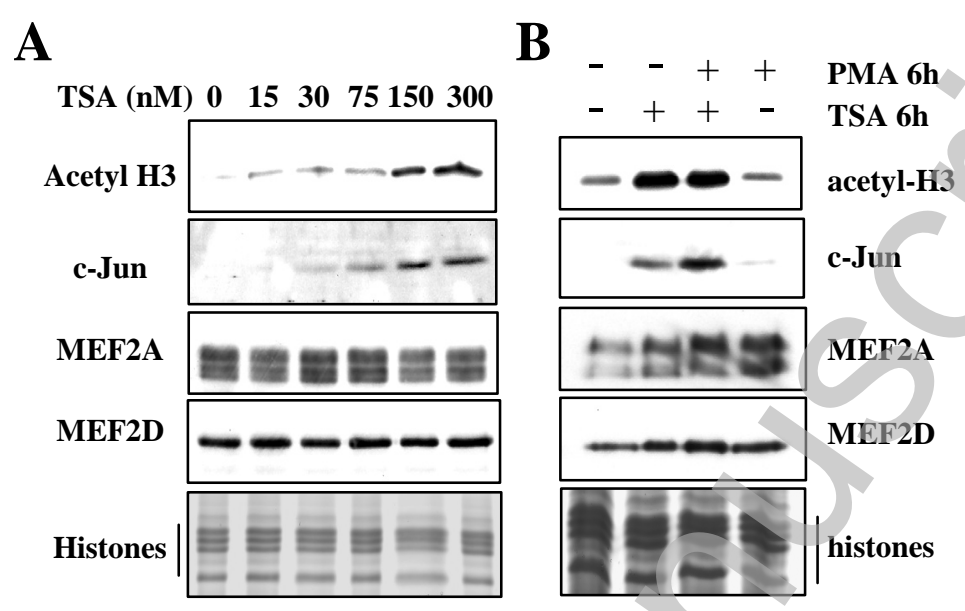

Figure 4 

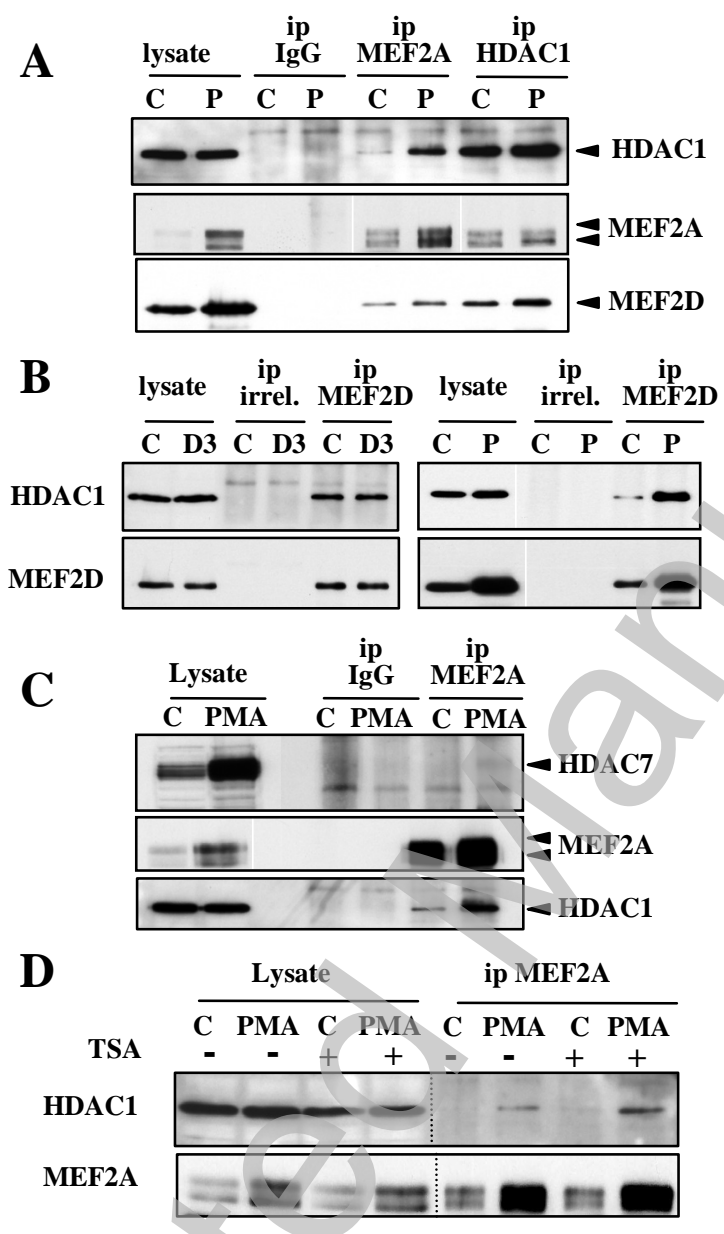

Figure 5

Licenced copy. Copying is not permitted, except with prior permission and as allowed by law. (C) 2010 The Authors Journal compilation (c) 2010 Portland Press Limited 


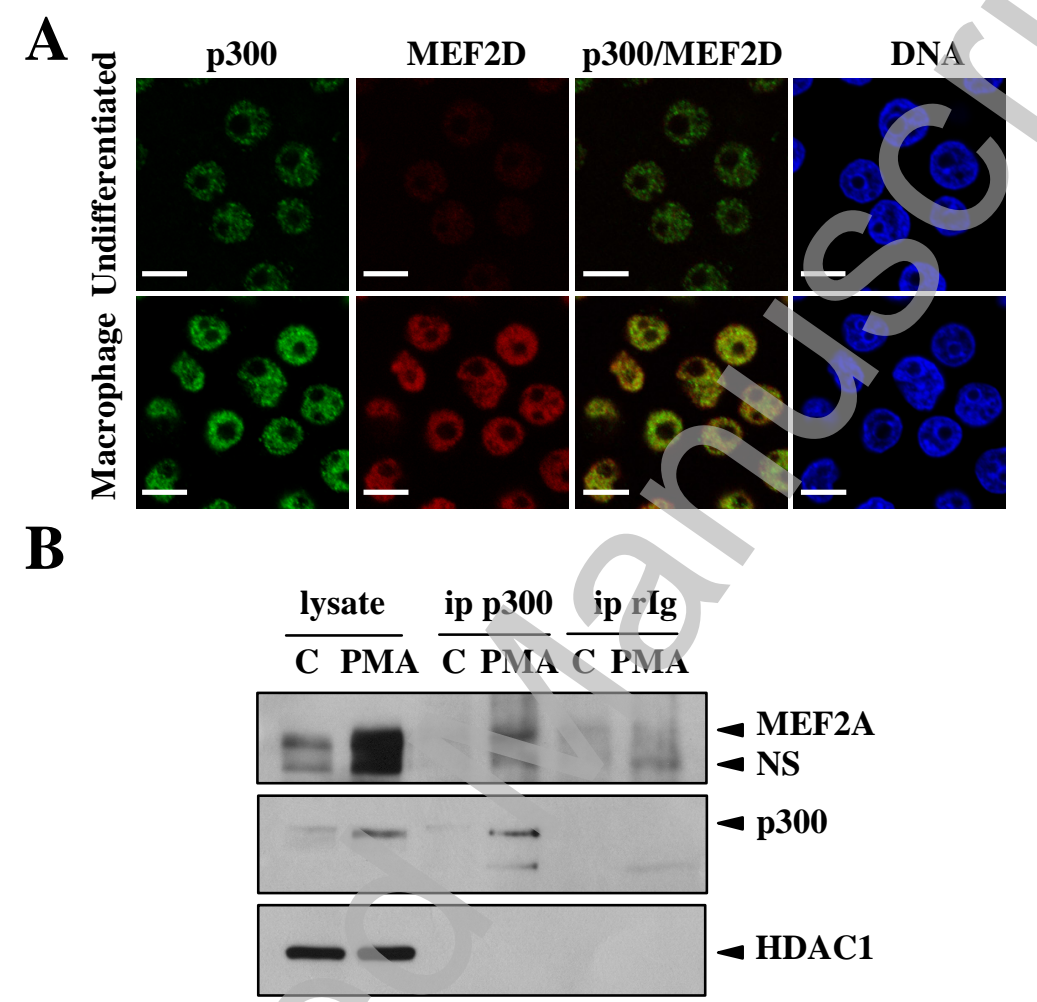

Figure 6 